\title{
Dimensions of Family Empowerment in Work with So-Called 'Troubled' Families
}

\author{
Sue Bond-Taylor
}

School of Social and Political Sciences, University of Lincoln

E-mail: sbtaylor@lincoln.ac.uk

The Troubled Families Programme has provided an impetus for interventions with families with multiple disadvantages. This article identifies the prevalence of a government discourse of 'empowerment' around such interventions, which fails to reflect the contested nature of the term. Qualitative interviews with families supported by the programme and their keyworkers offer an insight into their experiences and a valuable alternative to government rhetoric. It is argued that government discourses equate 'family empowerment' with responsibilisation, seeking to reduce the resources deployed in supporting families whilst strengthening state power to define acceptable forms of family life. By contrast, family and keyworker discourses of 'empowerment' are founded in the redistribution of resources towards such families, advocacy strategies, psychological support and an understanding of power relations within and beyond families, which enable families to resist specific attempts at the exercise of professional power, albeit remaining subject to a more general exercise of state control.

Keywords: Troubled families, family interventions, empowerment, responsiblisation.

\section{Introduction}

Successive governments have targeted 'dysfunctional' families, as the root cause of crime and anti-social behaviour, through strategic interventions, and the current Coalition government is no different. Its Troubled Families Programme reflects a renewed impetus to expand services in this area, and engage those families most hard to reach, building upon the Conservative Party manifesto commitment to provide 'targeted help to disadvantaged and dysfunctional families' (Conservative Party, 2010). The 2010 Comprehensive Spending Review initiated a programme to pilot 'community budgets' for supporting families with 'complex needs' within sixteen local authority areas, to test whether the pooling of resources expended on such families by local agencies would engender the provision of more efficient, joined up, and locally relevant services, alongside improved outcomes for families. In December 2011, the government announced an escalation of this strategy, establishing a dedicated Troubled Families Unit led by former 'Respect Tzar', Louise Casey, with $£ 450$ million of cross-government funding on a payments by results basis to local authorities tasked with 'turning around' the lives of 120,000 of the country's most 'troubled' families before the next general election (see Levitas, 2012, for a critique of this target number). This attractive financial prospect ensured that every local authority in the country agreed to participate in the programme. 
Whilst those local authorities with community budget pilots already in place effectively had a head start in establishing these services, they also faced the challenge of adapting their local approach to fit the new national model. In particular, this included a more prescriptive set of criteria by which to identify 'troubled families', namely families involved with crime and/or anti-social behaviour, with a child out of school and with an adult on out of work benefits. A fourth criterion of families causing high cost to the public purse was designed to allow some flexibility to address local concerns, where the first three criteria were to yield insufficient numbers of the estimated 120,000 'troubled' families. As Levitas (2012) identifies, this estimated figure of 'troubled families' was drawn from the Families at Risk report (Social Exclusion Task Force, 2007) using a different set of criteria relating to families with 'multiple disadvantages', focusing on broader concerns about the impact of poverty, inadequate housing, disability and mental ill-health, rendering a disconnect between the research base and policy development.

In announcing the Troubled Families Programme, Prime Minister David Cameron described the ways in which the programme would empower families: 'we will be empowering ... not making excuses for anyone, but supporting these families to take control of their own lives' (Cameron, 2011). This assumption that family interventions are empowering needs further scrutiny as there are myriad ways of understanding the concept, leading to its description as 'a chameleon "feel-good" term that means different things to different people' (Lister, 2004: 173).

This article explores the rhetoric and reality of family empowerment within such intervention strategies, by comparing government discourses of empowerment within the Troubled Families Programme with the experiences of so-called 'troubled families' and the professionals leading these interventions. This analysis illuminates the debate around family interventions in two ways: firstly, questioning the extent to which families are effectively empowered by the programme; and, secondly, what empowerment means in this context.

According to Morris et al. (2013: 457), 'remarkably little is known about the lived experiences of families facing severe and enduring difficulties' and therefore 'competing versions of the truth are all highly amenable to caricature and thus to increasingly amplified ideological skew'. Countering popular and political discourses about so-called 'troubled families' thus requires research which accesses these families' experiences of the complex problems they face and the family interventions to which they are subjected. Understanding family 'empowerment' also necessitates our understanding of family feelings of powerlessness and the contexts in which these form.

What we do know from research with vulnerable families to date is that families experience a feeling of powerlessness in the face of professional interventions. Davis' (2011) ethnography of families with complex needs describes the families' experiences of the apparently arbitrary exercise of state power, in which they are subject to decisions taken by others, and there is a pervading sense of 'lottery' in whether decisions fall in their favour, impeding future-oriented thinking and engagement with services. Similarly, Morris (2012) describes the gap which exists between vulnerable families' analyses of their own family life and the depiction offered by professionals working with them, consequently alienating families from the support being offered, or leading them to 'stage manage' family life in order to conform to professional interpretations. Relationships with social workers are experienced as particularly difficult, reflecting a form of surveillance and discipline without genuine communication or any scope for negotiation (Parr, 2009). 
Murray and Barnes (2010: 542) therefore encourage practitioners to 'negotiate a balance between institutional prescriptions of family and their lived experiences of what family means in practice' and to reflect upon the ways in which their responses to individual families are shaped by the dominant discourses used within their professional practice.

In a review of the family interventions literature, Parr (2011) has highlighted the dichotomous academic responses to family intervention services. Whilst evaluations of specific intervention projects have tended to find evidence of positive outcomes for families, these sit alongside more critical discussions, with concerns expressed about the rationale for support, the moralising tendencies of the projects, their disciplinary, punitive and stigmatising characteristics, the ways in which they individualise problems which have structural and material causes and their gendered focus. ${ }^{1}$ Nixon and Hunter draw our attention to the 'marked silence' (2009: 119) on the gendered use of behaviour control technologies within households headed by lone women, masked by the gender-neutral guise of 'parental' responsibility.

Yet Parr's research suggests that attempts to understand family interventions as wholly 'good' or 'bad' are unhelpful, as projects offer opportunities for both increased governance of vulnerable families, through strategies of self-regulation, and progressive support for families, based in social policy objectives. She advocates instead a deeper understanding of local practices which give rise to less punitive interventions and which are perceived by families as worthwhile (ibid.). Analyses of the potential for the Troubled Families Programme to empower families must therefore take place at a local level to understand the ways in which local practitioners interpret and implement central government's vision of Troubled Families interventions, and family experiences of this.

\section{Thinking about empowerment}

The term 'empowerment' has been widely used across a range of disciplines and prompts a good deal of terminological confusion due to the differing conceptualisations of power underpinning its various iterations (Larkin and Milne, 2014). However, Kuokkanen and Leino-Kilpi (2000) provide a useful typology, highlighting three key theoretical approaches: critical social theory, organisational theory, and social psychological theory, whilst Bradbury-Jones et al. (2008) add to this typology Foucauldian post-structuralist theory as a distinct fourth.

Critical social theory offers an approach which sees power as hierarchical, locating the power held by some social groups within their oppression of others (Kuokkanen and Leino-Kilpi, 2000). Power is exercised from above, thus empowerment processes can only be effected by disrupting and re-organising the hierarchy, a process of conscientisation and liberation from the oppressive exercise of power (Freire, 1986). Empowerment is therefore interpreted as a zero-sum, transferring power from one group to another. Critical evaluations of state discourses of empowerment interpret them as a means to mask existing hegemonic power relations (Westwood, 2002) and thus a politically expedient feature of neo-liberal economic agendas which promote greater community participation alongside more restrictive approaches to welfare (Mayo and Craig, 1995; Clarke, 2005; Mayo, 2004). 'Empowerment' in this sense involves little more than enabling the powerless to adjust to the consequences of economic restructuring (Lister, 2004; Mayo, 2004). Rowlands (1997) therefore identifies the control of resources as an important goal of empowerment 
strategies as it is through the ability to control material resources that the individual is able to exercise genuine control over their own life.

By contrast, organisational theories of empowerment focus on how individuals within organisational contexts might be empowered to fulfil organisational agendas, through the provision of opportunities, information, support and resources (Knol and van Linge, 2009). This structural empowerment takes place within existing power hierarchies, and empowerment is a process of delegation of power (Kuokkanen and Leino-Kilpi, 2000; Bradbury-Jones et al., 2008). It offers a degree of power to the individual, but contingent upon the continued consent/support of the powerful. The delegation of power therefore operates to placate the individual who is content with the level of power acquired and does not pursue further conflict or demands for power, thus rendering conflict 'unobservable' (Lukes, 1974). For critical commentators, therefore, empowerment is a form of ideology, maintaining power within the hands of the professionals with the aim of encouraging individuals to comply with certain agendas whilst also thinking that it was their idea (Skelton, 1994). Empowerment therefore depends upon your ability to adhere to a moral code and to do what 'you're supposed to do' (Wan et al., 2012: 403).

Social psychological approaches explore empowerment as a psychological development, in which an individual's self-belief, attitudes and motivations are central to the process of their empowerment (Kuokkanen and Leino-Kilpi, 2000). Empowerment strategies therefore act upon the individual's sense of agency and resilience (Thompson, 2007) without directly making changes to cultural or political arrangements which generate power differences (Bradbury-Jones et al., 2008). Adams (2008) questions whether psychological empowerment is sufficient in its own right; in other words, whether feelings of empowerment need to be transformed into more tangible actions and outcomes. However, Bartle et al. (2002) see tangible aspects of empowerment, requiring material resources, and intangible services which focus on quality of life and inter-personal relationships as symbiotic, with material resources providing the necessary context within which individuals can benefit from emotional support, whilst intangible services provide the 'humane qualities essential for effective tangible services' (ibid.: 36).

Post-structuralism, emphasising the numerous works of Michel Foucault in particular, has become widely used within literature on empowerment across a number of disciplines (Bradbury-Jones et al., 2008). Foucault's conceptualisation of power rejects top-down and zero-sum approaches which imply a finite quantity of power to be possessed by individuals and exercised from above. Instead, he understands power as relational, and intimately connected with the processes of knowledge production (Foucault, 1980). Individuals therefore need not be assigned to either powerful or powerless groups (Thompson, 2007), rather they simultaneously undergo and exercise power (Foucault, 1980). Empowerment work with families may consequently necessitate a detailed consideration of networks of power within the family (Tew and Nixon, 2010), and an awareness that 'empowerment cannot be shared equally across a family with multiple difficulties' (Adams, 2008: 105), but also surrounding the family, as communities become part of the broader governmental project of developing autonomous and self-regulating citizens (Flint, 2006).

Rowlands (1997) advocates the consideration of gendered power relations within any model of empowerment, combining critical social theory and social psychological perspectives to explore the ways in which internalised oppression creates barriers to women's exercise of power. This reflects concerns that the concept of power within critical theory in particular has been predominantly 'masculine', emphasising physical conflict 
and the seizing of power from another (Adams, 2008). Rowlands therefore incorporates into her analysis alternative feminist readings of power: firstly, power 'to' as a form of 'generative' power, i.e. that which stimulates activity and raises morale; and, secondly, 'power from within', i.e. that which acknowledges the capacity for inner strength and enables the individual to act in the face of overwhelming opposition. Empowering families (especially those headed by a lone mother) might therefore require prioritising women's empowerment, reconsidering what 'power' might mean for these women and what 'empowerment' might demand of them. Alternatively, proliferating problematic masculine discourses of power and agency may be less important in work with disadvantaged families than developing a feminist 'ethic of care' (Morris and Featherstone, 2010; Murray and Barnes, 2010), and there is a growing recognition of the value of this perspective in understanding effective practice in this area.

\section{Methods}

Data were collected for an evaluation of one community budget pilot on behalf of the local authority between January 2012 and April 2013, prior to, and during, the pilot's transition to a Troubled Families service (Bond-Taylor and Somerville, 2013). The service identified families for support through referrals from partner agencies based on locally agreed criteria for inclusion: at least one child or young person, a minimum of three needs or challenges, involvement from at least four agencies, with one agency involved for a minimum of twelve months. The project was underpinned by a family intervention model, characterised by the allocation of a dedicated keyworker to each family to offer a wraparound service, draw up a plan of support and co-ordinate the services involved with the family. The anticipated outcomes were reduced crime and anti-social behaviour, improved health and well-being, increased housing security and strengthened family resilience, improvements in the communities in which the families live and a reduction in the costs incurred by services in responding to families' needs.

As part of the evaluation strategy, semi-structured interviews were conducted with all fourteen (female) family keyworkers employed by the service at that time, and their two (female) practice supervisors, discussing aspects of the keyworker's role and their work with families. A second round of interviews was later undertaken to explore the development of the project and family progress.

Interviews were also conducted with twelve of the families supported by the team. A sample of families was selected for interview by the researchers, in consultation with the keyworkers. Given the vulnerability of these families, the complexities of their everyday lives and the emotional fragility of some family members, ethical considerations around harm avoidance were paramount. Three of the original selected families were unwilling to take part, and one family chose to withdraw from the service. The researchers followed up all twelve of the remaining families for a second interview to explore their progress, but only nine were available for a second interview. Interview location was decided by the family in collaboration with their keyworker and included the family home, the keyworker's office or an alternative service venue such as a children's centre. The family also decided whether they would prefer the keyworker to be present during the interview, with some families reassured by the presence of the keyworker to support them in contributing their experiences to the research, and remarking that there was nothing which could not be said in front of the keyworker anyway. 
While the intention had been to interview whole family groups for the research, this was difficult in practice, due to the fragmented nature of the families and children's unwillingness to take part. With nine families from the sample being headed by a lone female, mothers clearly acted as gatekeepers to the family and their voices do dominate here, with ten mothers interviewed, compared to two fathers and five young people.

\section{A comparison of discourses on family empowerment}

\section{Government discourse}

In launching the Troubled Families Programme, David Cameron described how family support would come from an army of workers providing 'a single point of contact for the first time for particular families - working out what the family needs, where the waste is and lining up the right services at the right time' (Cameron, 2011). It would provide an antidote to existing structures, described as 'essentially top-down and patronising' (ibid.). This discourse on empowerment therefore advocates ways of working in which families take control of the decision-making processes affecting them, in contrast to traditional coercive ways of working in which services make decisions on behalf of families, or in Cameron's words 'the state keeps doing things to families ... rather than working with them so they can change their lives' (ibid.). This interpretation of empowerment as a process of working with, not doing to (or for), by which individuals are enabled to take control over what happens to them is common within social work literature (Adams, 2008).

However, the approach from the Department for Communities and Local Government (2012) is that families 'have to take this intensive help', reflecting a lack of choice for families identified as 'troubled' and suggesting a continued exercise of power from above. Louise Casey, speaking at a national conference for Troubled Families co-ordinators in September 2012, described how the Troubled Families Programme would be different to earlier family interventions:

We have to be clear about who the families are that most need help to change and we have to be bold about getting past their front doors and we have to be tough about the consequences for them if they say they don't want help. (Casey, 2012a)

David Cameron's language of 'working with' rather than 'doing to' contrasts sharply with Louise Casey's rhetoric, which frames the family as object (rather than subject). She describes, for example, the number of families who, in spite of previous state interventions 'have not been changed' (rather than have not changed), and relates the experiences of one family who 'has been worked with intensively by a trained skilled worker' (rather than who has been working intensively with such a worker) (Casey, 2012a). This reinforces a sense of the passivity and powerlessness of these families and echoes the stigmatising discourse of so-called 'troubled families' as inactive and unproductive, leading, in Casey's words to, 'a life spent on the settee' (2012a). This depiction of a 'Shameless culture' (Cameron, 2011) within public debates reflects Levitas' (2012) concerns about the shift in discourse in this area from depictions of families at risk, or in need, to those who are troubled, which she argues is more commonly translated to mean trouble. The vulnerability, disadvantage and exclusion experienced by these families are often forgotten within this 
public discourse, which operates as a means of 'othering' (Lister, 2004), through which the poor are constructed as 'irresponsible, criminal or inadequate' (Lister, 2004: 122), and thus reinforces existing social and economic demarcations.

One of the core aims of 'troubled families' interventions is to reduce the extensive levels of service involvement within such families and thus the high cost to the public purse. The objective is to achieve this by 'empowering' families with complex needs to take on greater levels of responsibility for the effective functioning of the family, as illustrated by David Cameron's comments advocating 'a clear hard-headed recognition of how the family is going wrong - and what the family members can do to take responsibility' (Cameron, 2011). Here we see Cameron's project of empowerment slipping into the rhetoric of responsibilisation, as if the two could be straightforwardly equated:

We will not fix these problems without a massive revolution in responsibility ... a recognition that we need in our country a massive step change in accepting personal responsibility, parental responsibility, and social and civic responsibility. (ibid.)

The ways in which empowerment strategies and responsibilisation strategies may collide need further consideration, particularly where services hold individuals responsible for problems which they do not have the power to influence, or where their capacity to exercise such power is severely limited. The Troubled Families Programme, for example, acknowledges the prevalence of depression and mental health problems among the families being targeted (Casey, 2012b), but the process of building the psychological capacity of individuals as a means of generating action and outcomes is not considered sufficiently important to feature within the 'five family intervention factors' advocated in work with so called 'troubled families' (Department for Communities and Local Government, 2012). ${ }^{2}$

\section{Keyworker discourse}

Comments made by the family keyworkers resonate with Cameron's vision of family empowerment, for example, 'They don't see us as enforcers ... They see us more as somebody who is there to empower them to change their own lives.' Their comments also reflect the aims of responsibilisation evident in the government's 'Troubled Families' discourse, supporting families with the short-term objectives of addressing immediate presenting problems, but also the longer-term objective of building family capacity to deal with future problems, and taking responsibility for accessing universal services. According to one keyworker:

What we aim to do is to get the families to a state where they're maintaining the issues in their own home, and they're not escalating, and that they can make phone calls to whoever it is they need to, they can attend the appointments, you know, they can feel assertive enough to phone the school and explain about why their child is not going to be in that particular day.

Keyworkers articulate their belief that the service is empowering for its service users, and that they are 'working with, not doing to', describing their work as 'family-led with an agency steer as opposed to agency-led with the family dragged along'. As one keyworker eloquently noted: 
It feels as if they're writing the story, and they've got a pen and paper in their hand. They're writing the story, and I'Il be holding the edge of the paper, to keep it still.

However, this raises the question of the degree of 'agency steer' which can be levied upon a family before the project ceases to be 'family-led'. As one member of the team described it:

We work very closely with them and get them on board, put the ideas into their head that make it as though they've kind of thought about the idea.

Family keyworkers demonstrate themselves to be very skilled at identifying the concerns which need to be addressed in order to satisfy the demands of other agencies, whilst encouraging families to take ownership of those concerns so that they too prioritise these issues. The keyworkers therefore support the family to identify the most pressing issues, and offer reassurance about how these may be resolved, promoting family engagement and co-operation in the process.

Ours is family led in terms of how they want to prioritise, how they want to do it, what they want to tackle first. We can give them a bit of a shove and say 'Don't you think we need to do this to make sure that you're not losing your property.'

These comments illustrate the grey area between family intervention approaches which promote the participation of family members (for example, to sign a support plan and consent to interventions) and those which empower families to shape the intervention, to define their concerns and to challenge what they perceive to be oppressive practices. Somerville (1998: 234) argues that participation without empowerment is a confidence trick, and that 'To the extent to which the trick works, it must be disempowering rather than empowering.' Services working with disadvantaged families should therefore reflect upon the extent to which family participation in the process merely legitimates existing power relations under a veneer of empowerment discourses, and how some families may be especially vulnerable to this.

The keyworkers' comments reflected notions of psychological empowerment, stressing the need to build self-esteem and encourage family members to see what they were capable of achieving, emphasising the importance of being constructive rather than negative and demotivating:

So it's really constructive comments that you're giving all the time. And that's how you build it. That's how you build a new relationship, because you're not there to put them down, you're in there to build them up.

However, they also talked about their role as advocate, empowering family members to have their voice heard, and holding other services responsible for giving support where necessary, and chasing up inaction on behalf of the family, particularly where individual services or systemic operations have failed them in the past:

We advocate for the families, you know we are the voice sometimes if they don't feel that they have one. And we can give them the forum and get them speaking to the right people. 
Everybody else is going, 'Oh that's not our responsibility, not our responsibility'. You know we can actually step in and say either 'It's your responsibility and we want you to do it' or actually, 'Right, just do it'.

Furthermore, there was an awareness by keyworkers and project managers of the ways in which improving family outcomes required economic resources, and the service therefore included a budget for spending on items which would help the family to move forward, such as skip hire, school uniform, second hand beds and white goods. However, control of these material resources remained largely in the hands of the keyworkers, who prioritised spending where they identified need, reflecting official interpretations of what constitute the 'building blocks of an orderly home and a responsible life' (Cameron, 2011). Additionally, resources were often offered as a reward for compliance with other requirements within the interventions, for example, school attendance, debt management, or child protection, reinforcing the differential distribution of power over resource allocation.

\section{Family discourse}

The referral criteria for the project meant that all of the families had considerable previous service involvement going back many years, with large numbers of services involved at any one time, and frequent changes in personnel visiting the household. They had experienced this as being contradictory and unhelpful:

At one time we had eleven different ... services on, and take it from me it was one big chaos. (Dad)

For many of the families, this was characterised by particularly difficult relationships with Social Services, who they felt exemplified very distanced ways of working, which demonstrated a lack of commitment to the family. Social workers were seen as intimidating and authoritarian, and families were concerned about the ways in which they were constructed within social workers' case notes, which then became viewed as objective facts:

If I said anything, they'd write it up as in like I said this, but make it ten times worse. Yeah, it was horrible. (Mum)

Social workers, because it says it, then that's true, they don't actually get to know the family. (Mum)

Families were therefore sceptical about referral to an intensive family intervention programme ('another do-gooder') and its potential for support, being reluctant to consent to the referral, but feeling as though they had little choice. 'Troubled families' interventions could therefore be interpreted as increasing the power exercised over already vulnerable families through the emphasis on securing engagement regardless of whether families wanted to be engaged. The threat of sanctions used to engage families reinforces their powerlessness, perceived by one of the families as, 'like a blackmail type of thing' (Dad). 
Families were, however, quick to comment on the difference between the keyworker, in their efforts to get to know the family, and other professionals they had encountered, illustrating the ways in which keyworkers explore the lived experiences of the families with which they work:

social workers ... me and my dad agree on it, they treat us like a case and stuff, but [keyworker], she treats us as a family, and she just knows where we're coming from for some reason. (Daughter, 11)

Families appreciated the advocacy dimensions of the keyworker role, providing a buffer between the family and enforcement professionals, which relieved the pressure from families and gave them some breathing space:

When Social Services get involved you're very nervous, you know, are they going to take the children away? All sorts of things run into your head, don't they? But I find with my keyworker I don't have to worry about that because she's there to support me and I know that my children are not going to get taken off me ... and that I'm not there on my own, I don't have to battle everything on my own. (Mum)

Consequently, families were able to build more constructive relationships with their social worker, and improved engagement with a range of services was a clear outcome for all families. For many families, however, the goal was still to be able to manage without service involvement as a matter of pride, suggesting that family (or more specifically, parental) goals did not differ dramatically from government responsibilisation agendas:

I'm trying to get them where they're not coming in so often, I want to try and do it on my own without no back-up. (Mum)

Families, therefore, wanted to be supported to be able to retake control of their family lives. For the families interviewed, psychological development was central to their description of the processes of empowerment and the subsequent positive outcomes they experienced. Family members recounted how they had felt unable to deal with some of the difficulties that they had faced in their complex lives due to their own lack of confidence, as one mother described:

I was too low in self-esteem to really want to go out the house and everything and I wouldn't answer the door. (Mum)

For a considerable number of the families interviewed, this was connected with a history of victimisation, including long-standing domestic abuse, bullying at school and intimidation by other members of the local community. Confidence building was therefore central to the work of the family keyworker in empowering family members to be able to make decisions and take positive action in their own interests, for example:

I was happy every day because I loved helping myself. I found it really good that I was doing it, because it's something that I never done before. (Son, 18) 
The keyworkers were described by the families as providing motivation and a 'boot up the bum' (Mum), giving them 'the will to carry on' (Mum) when they felt like giving up. This reflects forms of empowerment underpinned less by a notion of gaining power 'over' others, and more concerned with power 'to' or power 'from within' (Rowlands, 1997; Thompson, 2007). Gendered power relations emerge as an important feature of work with disadvantaged families and a considerable proportion of the families included within the research were headed by a single mother suffering from depressive illness and other mental health concerns, often associated with a long history of domestic abuse. Empowering the mother to end violent relationships therefore entails a shift in power within the home and family keyworkers support family members to rebalance power relations in this way:

I was in an abusive relationship, very abusive. He would throw things, break things, there was not a lot he didn't do really to be honest. The house was always a mess. The kids weren't happy at all ... If [my keyworker] hadn't been around, I don't think I would have got rid of him. Or it would have been too late and the kids would have gone [into care] ... I suppose I realised that I couldn't take it anymore and I think that knowing [my keyworker] was there for support ... that I'd be able to do it. (Mum)

A number of mothers talked about the ways in which their abusive and controlling partners prevented them from making positive changes within the home, whether that be undertaking everyday chores or decorating and home improvements. Practitioners therefore need to be mindful that these new technologies of control do not perpetuate private and public patriarchies by holding mothers responsible for aspects of family life over which they have little control (Nixon and Hunter, 2009). Understanding the limits to personal agency within networks of family power is central to such work.

The complexities of power relations within marginalised communities may also impact upon any empowerment work within family interventions, and practitioners need to reflect upon how to support families within the environments of their 'social economy' (Mitchell and Campbell, 2011). A number of family interviews discussed the disputed nature of neighbour complaints, and families often felt victimised by others in the local area:

Every other week we used to get our windows put through, brick through the window, and it is really scary. (Mum)

Empowering disadvantaged families therefore further needs to consider the extent to which families are able to challenge community responses, rather than merely conform to community expectations, which may reflect an intolerance of the vulnerable 'other'.

\section{Conclusions}

An analysis of qualitative interviews with families facing multiple disadvantages illuminates the complexity involved in the task of promoting their empowerment through intensive family interventions. Government discourses around so-called 'troubled families' tend to equate empowerment with responsibilisation and seek to reduce the resources employed in their support. By contrast, alternative conceptualisations of 
empowerment are founded in the redistribution of resources towards such families (and the communities which they inhabit), particularly in the face of the rationalisation of public spending.

Projects promoting the empowerment of the family often strengthen existing power relations between family and local authority services. 'Troubled Families' projects work to build bridges between families and services, where they have become eroded through an extended history of intervention and coercion. Families are 'empowered' only in so much as they are compliant and accept the normalising discourses of the services through engagement with their agendas for change. Family empowerment, therefore, may enable the family to resist specific attempts at the exercise of power and control by certain agents of the state (such as removal of the children from the family home) whilst remaining subject to a more general exercise of state power through the continued dominance of prevailing discourses around family life and parental responsibility.

Empowerment strategies should therefore not focus solely on the individuals or groups to be empowered, but also upon the services and professionals where power is held in order to identify stigmatising or obstructive practices which limit the opportunities for service users to be heard. Empowerment must include strategies of advocacy which voice the needs and wishes of the family or individual where they lack the resources to represent themselves.

Psychological empowerment strategies are also vital in building family confidence, capacity and resilience. The fundamental importance of emotional well-being must be recognised by practitioners, both as a means of securing future engagement with services to achieve longer-term goals, and as an objective in its own right. The flexibility within this community budget project allowed keyworkers to adopt relationships with families which prioritised intangible aspects of well-being. It is unfortunate that the move to the Troubled Families programme, and its more restrictive payments by results focus on anti-social behaviour, education and employment, might threaten such flexibility.

\section{Acknowledgements}

I would like to thank both my colleagues at the University of Lincoln and the anonymous reviewers for their useful comments on earlier drafts of this article. Special thanks must also go to the families and practitioners for their participation in the research.

\section{Notes}

1 See in particular Garrett's (2007a) critique of Dillane et al.'s (2001) evaluation of the Dundee Families Project, and the subsequent rejoinders by Nixon (2007), Bannister et al. (2007) and Garrett (2007b) for a useful illustration of this dichotomy.

2 The five family intervention factors are: 1. Dedicated workers, dedicated to families; 2 . Practical 'hands on' support; 3. A persistent, assertive and challenging approach; 4. Considering the family as a whole; 5. A common purpose and agreed action (Department for Communities and Local Government, 2012).

\section{References}

Adams, R. (2008) Empowerment, Participation and Social Work, 4th edition, Basingstoke: Palgrave Macmillan. 
Bannister, J., Hill, M. and Scott, S. (2007) 'More sinned against than sinbin? The forgetfulness of critical social policy?', Critical Social Policy, 27, 4, 557-60.

Bartle, E. E., Couchonnal, G., Canda, E. R. and Staker, M. D. (2002) 'Empowerment as a dynamically developing concept for practice: lessons learned from organizational ethnography', Social Work, 47, $1,32-43$.

Bond-Taylor, S. and Somerville, P. (2013) Evaluation of Families Working Together: Final Report, Lincoln: University of Lincoln, http://eprints.lincoln.ac.uk/12527/1/FWT\%20Evaluation\%20Final\% 20Report\%2010_06_2013.pdf (accessed 23 June 2014).

Bradbury-Jones, C., Sambrook, S. and Irvine, F. (2008) 'Power and empowerment in nursing: a fourth theoretical approach', Journal of Advanced Nursing, 62, 2, 258-66.

Cameron, D. (2011) 'Full transcript, David Cameron, Speech on Troubled Families, Sandwell Christian Centre, Oldbury, 15 December 2011', New Statesman, 15 December, http://www.newstatesman. com/uk-politics/2011/12/troubled-families-family (accessed 23 June 2014).

Casey, L. (2012a) 'Speech Delivered to the National Conference of Troubled Families Co-ordinators', Coin Street Neighbourhood Centre, South Bank, London, 18 September.

Casey, L. (2012b) Listening to Troubled Families: A Report by Louise Casey CB, London: Department for Communities and Local Government, https://www.gov.uk/government/uploads/system/ uploads/attachment_data/file/6151/2183663.pdf (accessed 23 June 2014).

Clarke, J. (2005) 'New Labour's citizens: activated, empowered, responsibilised, abandoned?', Critical Social Policy, 25, 4, 447-63.

Conservative Party (2010) Invitation to Join the Government of Britain, Conservative Manifesto 2010, Uckfield: Pureprint, http://www.conservatives.com//media/Files/Activist\%20Centre/Press\% 20and\%20Policy/Manifestos/Manifesto2010 (accessed 23 June 2014).

Davis, B. (2011) The Need for a New Approach: Developing an Ethnographic Understanding of Families with Complex Needs, A report for Leicestershire Together, 18 October, http://www. leicestershiretogether.org/211111_ethographer_report.pdf (accessed 23 June 2014).

Department for Communities and Local Government (2012) Working with Troubled Families: A Guide to Evidence and Good Practice, London: DCLG, https://www.gov.uk/government/uploads/system/ uploads/attachment_data/file/66113/121214_Working_with_troubled_families_FINAL_v2.pdf (accessed 23 June 2014).

Dillane, J., Bannister, J. and Scott, S. (2001) Evaluation of the Dundee Families Project - Final Report, Edinburgh: Scottish Executive.

Flint, J. (2006) 'Housing and the new governance of conduct', in J. Flint (ed.), Housing, Urban Governance and Anti-Social Behaviour, Bristol: The Policy Press, pp. 19-36.

Foucault, M. (1980) Power/Knowledge: Selected Interviews and Other Writings, 1972-1977, edited by Colin Gordon, London: Harvester.

Freire, P. (1986) Pedagogy of the Oppressed, Harmondsworth: Penguin.

Garrett, P. M. (2007a) "Sinbin" solutions: the "pioneer" projects for "problem families" and the forgetfulness of social policy research', Critical Social Policy, 27, 2, 203-30.

Garrett, P. M. (2007b) "Sinbin" research and the "lives of others": a rejoinder in an emerging and necessary debate', Critical Social Policy, 27, 4, 560-4.

Knol, J. and van Linge, R. (2009) 'Innovative behaviour: the effect of structural and psychological empowerment on nurses', Journal of Advanced Nursing, 65, 2, 359-70.

Kuokkanen, L. and Leino-Kilpi, H. (2000) 'Power and empowerment in nursing: three theoretical approaches', Journal of Advanced Nursing, 31, 1, 235-41.

Larkin, M. and Milne, A. (2014) 'Carers and empowerment in the UK: a critical reflection', Social Policy and Society, 13, 1, 25-38.

Levitas, R. (2012) There May Be 'Trouble' Ahead: What We Know about Those 120,000 'Troubled' Families, PSE UK Policy Working Paper No. 3, 21 February, http://www.poverty.ac.uk/sites/default/ files/attachments/WP\%20Policy\%20Response $\% 20$ No.3-\%20\%20\%27Trouble $\% 27 \% 20$ ahead $\% 20 \%$ 28Levitas\%20Final\%2021April2012\%29.pdf (accessed 23 June 2014). 
Lister, R. (2004) Poverty, Cambridge: Polity Press.

Lukes, S. (1974) Power: A Radical View, Basingstoke: Macmillan.

Mayo, M. (2004) 'Exclusion, inclusion and empowerment: community empowerment? Reflecting on the lessons of strategies to promote empowerment', in J. Anderson and S. Birte (eds.), The Politics of Inclusion and Empowerment: Gender, Class and Citizenship, Basingstoke: Palgrave Macmillan.

Mayo, M. and Craig, G. (1995) 'Community participation and empowerment: the human face of structural adjustment or tools for democratic transformation', in G. Craig and M. Mayo (eds.), Community Empowerment: A Reader in Participation and Development, London: Zed Books, pp. 1-11.

Mitchell, G. and Campbell, L. (2011) 'The social economy of excluded families', Child and Family Social Work, 16, 4, 422-33.

Morris, K. (2012) 'Troubled families: vulnerable families' experiences of multiple service use', Child and Family Social Work, 18, 2, 198-206.

Morris, K. and Featherstone, M. (2010) 'Investigating children, regulating parents, thinking family: a decade of tensions and contradictions', Social Policy and Society, 9, 4, 557-66.

Morris, K., White, S. and Featherstone, B. (2013) 'Introduction. Themed section: approaches to families with complex needs', Families, Relationships and Societies, 2, 3, 457-8.

Murray, L. and Barnes, M. (2010) 'Have families been rethought? Ethic of care, family and "whole family" approaches', Social Policy and Society, 9, 4, 533-44.

Nixon, J. (2007) 'Deconstructing "problem" researchers and "problem" families: a rejoinder', Critical Social Policy, 27, 4, 560-4.

Nixon, J. and Hunter, C. (2009) 'Disciplining women: anti-social behaviour and the governance of conduct', in A. Millie (ed.), Securing Respect: Behavioural Expectations and Anti-Social Behaviour in the UK, Bristol: The Policy Press, pp. 119-38.

Parr, S. (2009) 'Family intervention projects: a site of social work practice', British Journal of Social Work, 39, 7, 1256-73.

Parr, S. (2011) 'Family policy and the governance of anti-social behaviour in the UK: women's experiences of intensive family support', Journal of Social Policy, 40, 4, 717-37.

Rowlands, J. (1997) Questioning Empowerment: Working with Women in Honduras, Oxford: Oxfam.

Skelton, R. (1994) 'Nursing and empowerment: concepts and strategies', Journal of Advanced Nursing, 19, 3, 415-23.

Social Exclusion Task Force (2007) Families at Risk: Background on Families with Multiple Disadvantages, London: Cabinet Office, http://webarchive.nationalarchives.gov.uk/20090114000528/http:/ cabinetoffice.gov.uk/media/cabinetoffice/social_exclusion_task_force/assets/families_at\%20_risk/ risk_data.pdf (accessed 23 June 2014).

Somerville, P. (1998) 'Empowerment through residence', Housing Studies, 13, 2, 233-57.

Tew, J. and Nixon, J. (2010) 'Parent abuse: opening up a discussion of a complex instance of family power relations', Social Policy and Society, 9, 4, 579-89.

Thompson, N. (2007) Power and Empowerment, Lyme Regis: Russell House.

Wan, C. R., Vo, L. and Barnes, C. S. (2012) 'Conceptualizations of patient empowerment among individuals seeking treatment for diabetes mellitus in an urban, public-sector clinic', Patient Education and Counselling, 87, 3, 402-4.

Westwood, S. (2002) Power and the Social, London: Routledge. 